\title{
INJA BUNGAKU - CONSIDERAÇÕES SOBRE A LITERATURA DOS RETIRADOS DA ERA CHÛSEI
}

Luiza Nana Yoshida

RESUMO: Este artigo propõe uma reflexão sobre a Literatura dos Retirados da época Chûsei (séculos XII-XVI), produzida por autores que viveram, em retiro, afastados da sociedade, e buscaram na doutrina budista o Caminho Verdadeiro da Vida.

ABSTRACT: This article intends to reflect upon Literature of Retired of Chûsei era (12th-16th centuries), produced by authors that retired from the world, and look for the Truth Way of Existence in the Buddhist doctrine.

PALAVRAS-CHAVE: Literatura Chûsei, Inja, Literatura Sôan, Literatura e Budismo, Efemeridade.

KEYWORDS: Chûsei Literature, Inja, Sôan Literature, Literature and Buddhism, Ephemerality.

Inja (literalmente "a pessoa que se oculta") "refere-se àquele que, através do retiro, abandona o mundo terreno e dedica-se à prática da disciplina espiritual, livre de qualquer compromisso com a sociedade" (Miki, 1983, p. 246). Uns vivem isolados nas montanhas, em rústicas cabanas, outros peregrinam por várias localidades e, numa demonstração de completo desprendimento, cortam vínculos com a família, abandonam posições socias e os bens materiais. Na época Chûsei (1185-1573), devido, entre outros fatores, à intranqüilidade política de então, encontramos uma profusão dos chamados inja, muitos dos quais dedicaram-se à atividade literária, tornando-se, desse modo, importantes sustentáculos da literatura, tal qual as damas da Corte (nyôbô), na época 
Heian (794-1185) e os comerciantes (chônin), na época Edo (1603-1868)'. Assim, os inja foram responsáveis pela produção de obras incluídas dentro do gênero denominado Inja Bungaku (Literatura dos Retirados) ou Sôan Bungaku (Literatura da Cabana), permeado essencialmente pela concepção budista da efemeridade (mujô).

\section{Era Chûsei}

A era denominada Chûsei (Idade Média) abrange duas épocas históricas marcantes, a saber:

a) Época Kamakura (1185-1333)

b) Época Muromachi (1333-1573) $\left\{\begin{array}{l}\text { período Nanbokuchô (1333-1392) } \\ \text { período Sengoku (1467-1568) }\end{array}\right.$

Contrastando com a época anterior, Heian, marcada por um período de paz, na medida em que não existe o registro de nenhuma rebelião interna mais contundente, na época Kamakura, contrariamente, assistimos à gradativa ascensão da classe guerreira $e$ o início de um período bastante conturbado, que culmina com o total esfacelamento do país, como resultado de mais de um século de guerras internas.

Desde o fim do século XII, quando Minamoto no Yoritomo (1147-1199) instalou seu quartel-general em Kamakura, o Japão passou a ter dois governos, o civil e o militar, que mantiveram, na época de Yoritomo, uma convivência relativamente pacífica. Após a sua morte e $o$ assassinato de seus filhos, o comando militar passa para as mãos dos Hôjô, família da esposa de Yoritomo. Aproveitando-se do momento de instabilidade do governo militar, o ex-imperador Go-Toba (1180-1239) lidera, em 1221, uma rebelião, Jôkyû no ran, visando a derrubada do governo militar. A rebelião foi, no entanto, controlada pelo exército dos Hôjô, que ocupou Quioto. Os Hôjô destronaram o imperador de então, substituindo-o por um outro que atendia a seus interesses, e ordenaram o desterro do ex-imperador Go-Toba, assim como dos outros dois ex-imperadores, para ilhas remotas. Essa vitória foi significativa para o bakufu (governo militar) que instalou uma força especial em Quioto, para vigiar os passos da Corte, confiscou os domínios daqueles que se aliaram ao grupo de Quioto e distribuiu-os aos guerreiros (bushi) que se destacaram em combate. Como conseqüência, a autoridade política da nobreza sofreu sério golpe e o sistema shôen (grandes glebas particulares pertencentes à Corte, nobreza e ao clero, e que constituíam a base econômica dessas classes) càminha para a deterioração, devido principalmente ao direito adquirido pelos comissários de terra de ocuparem parte do shôen que fiscalizavam. O governo de Kamakura consegue, assim, consolidar o seu poder, mas é derrubado, em 1333, devido às contradições internas do regime, que se acentuaram, após as invasões mongóis (1274 e 1281) e, sob a pressão da Corte, liderada pelo imperador Go-Daigo (1288-1339), com o auxílio de poderosos bushi, descontentes com a política dos Hôjô.

1. Sumito Miki, "Inja" ("Retirado"), Nihon Koten Bungaku Daijiten (Grande Dicionário da Literatura Clássica Japonesa), vol. 1. Tóquio, Iwanami, Shoten, 1983, p. 246. 
O breve período em que o poder volta às mãos da Corte é conhecido como Restauração Kenmu, mas, Ashikaga Takauji, chefe bushi que auxiliara o imperador Go-Daigo a derrubar o governo de Kamakura, insatisfeito com o rumo político tomado pelo imperador, instala o governo militar, em Quioto, dando início à época denominada Muromachị. O Japão passa a ter, então, um governo militar e duas Cortes, a do Norte, em Quioto, sob a proteção de Takauji, e a do Sul, em Yoshino, para onde se refugiara o imperador Go-Daigo, sendo esse período conhecido como Nanbokuchô (Corte do Norte e do Sul), que perdura por cerca de sessenta anos. Os vários grupos bushi ora aliam-se a Takauji, ora a Go-Daigo, conforme seus interesses, até que, em 1392, Go-Daigo é derrotado, enfraquecendo, ainda mais, o poder da Corte e da nobreza.

Em 1467, na época de Ashikaga Yoshimasa, oitavo shogun (chefe do governo militar) da época Muromachi, a rivalidade entre dois grandes grupos bushi, Hosokawa

e Yamana, vai ser o estopim de uma guerra interna, conhecida como Revolta de Ônin, que se estende por mais de dez anos, e destrói grande parte de Quioto, transformada num campo de batalha. Mesmo após a Revolta de Ônin, o Japão não vê cessar as lutas internas, que se alastram por todo o país. Trata-se da luta travada entre os vários senhores feudais que, na época da Revolta de Ônin, lutavam pelos Hosokawa ou pelos Yamana, mas que, agora, defendiam e procuravam ampliar, cada qual, os seus domínios. Esse período, denominado Sengoku jidai (período das guerras civis), perdura por quase um século, levando o país ao total esfacelamento.

Como se vê, a era Chûsei foi marcada por intermináveis guerras internas que causaram, além da instabilidade político-social, uma intranqüilidade emocional que coincide com a conscientização da aproximação da época da decadência, advinda da idéia de Mappô, ou seja, a idéia da cessação da lei de Buda, mil anos após a sua morte, o que causa a busca por auxílios alternativos como a religião, e propicia a ampla aceitação de seitas que pregam a salvação pós-morte ou a concepção budista da efemeridade (mujô). Assim, na era Chûsei, a vida terrena era considerada efêmera e o mundo terreno, ukiyo, ou seja, um "mundo triste" o que levou muitos a buscar a existência baseada numa verdade interior, "retirando-se do mundo"e tornando-se inja.

\section{Formação da Literatura dos Retirados}

No decorrer da História japonesa, é possível distinguir cinco modalidades de "vida em retiro":

1) desiludido com a existência atual ou afastado do mundo presente, cortar, passiva ou ativamente, laços com a sociedade e viver retirado em montanhas ou florestas;

2) experimentar temporariamente uma vida em retiro, de caráter apreciativo, influenciado pela filosofia chinesa como a de Lao-tze;

3) por influência do pensamento budista, praticar exercícios disciplinadores, em retiro ou, o monge budista viver uma existência peregrina ou reclusa, afastando-se das relações sociais;

4) literatos convertidos, tomar hábitos budistas e realizar a prática de uma vida peregrina ou reclusa em cabana; 
5) de maneira geral, viver uma existência reclusa temporária, levado por uma postura literária apreciativa (Shiraishi, 966, p. 10).

$O$ anseio por uma vida em retiro é um tema que já pode ser encontrado em obras do século VIII, como a antologia poética Man'yôshû (Antologia das Dez Mil Folhas), mas este encontra-se ainda fortemente ligado às raízes chinesas, portanto de característica muito mais filosófica do que religiosa, tendo em vista que esse estilo de vida era atribuído a pessoas especiais como aqueles considerados sábios.

Os chamados inja da época Chûsei, conforme pode ser visto, a seguir, na definição sobre a "Literatura dos Retirados" contida no Grande Dicionário da Língua Japonesa, possuíam uma estreita relação com o Budismo e, preenchem as características levantadas na modalidade (4) acima citada.

A Literatura dos Retirados é definida, então, nos seguintes termos:

Refere-se, dentro da História da Literatura do Japão, à literatura produzida pelos inja, presentes, em grande número, durante a época Chûsei. Tendo como base a visão da efemeridade budista, seus autores, isolados em seu universo particular, mostram forte tendência críticaespeculativa com relação à sociedade. (Umezaki, 1989, p. 151.)

Já com relação ao termo inja, consta que a sua utilização, durante a época Chûsei, é rara, sendo, seus sinônimos, yosutebito ("pessoa que abandona o mundo") ou tonseisha (eremita), mais usuais ${ }^{2}$.

O poeta e crítico Orikuchi Shinobu (1887-1953) é citado como o pioneiro na sua utilização como termo literário. Orikuchi lembra, em seu trabalho ${ }^{3}$ que, desde a Antiguidade, a servidora graduada dos grandes clãs, qualificada como miko $o^{4}$, possuía a função de transmitir, aos súditos, as ordens do senhor. As damas da Corte da época Heian possuíam uma função semelhante, ao registrarem e transmitirem as vontades imperiais. Orikuchi faz as referidas colocações, com o intuito de explicar a presença apenas da palavra nyôbô (dama da Corte), no lugar do nome do autor, em alguns dos poemas incluídos na competição poética denominada uta awase. Ele deixa claro que fica difícil afirmar simples e categoricamente se, nessas competições, a palavra nyôbô teria sido utilizada com o sentido de "senhora" ou "dama da Corte" que registrou o poema em nome da senhora a quem serve. De qualquer forma, escrever sob pseudônimo ou não utilizar o nome de nascimento era prática freqüentemente adotada, desde os tempos antigos. Assim, Orikuchi considera como uma das razões dessa prática, pelo menos no fim da época Heian, o fato de a alta aristocracia, que começava a dar mostras de grande interesse pelo mundo das classes mais baixas, ainda que a nível de curiosidade, espelharem-se nos inja que, no lugar de seus nomes familiares, passam a ser conhecidos pelos nomes budistas, como um sinal de desapego ao status ou carreira profissional, o que lhes proporcionava um sentimento de maior despojamento e liberdade.

2. Idem, ibidem.

3. Shinobu Origuchi, "Nyôbô Bungakukara Inja Bungakue" ("Literatura das Damas da Corte para a Literatura dos Retirados"). Origuchi Shinobu Zenshû, vol. 1, Tóquio, Chûô Kôronsha, 1965, pp. 265-320.

4. Miko - jovem sacerdotisa considerada mensageira das divindades xintoístas. 
No que se refere às manifestações artísticas, Orikuchi lembra a efusiva aceitação de artes originariamente populares como kouta, zôgei e imay $\hat{o}^{5}$, por parte da nobreza. No que tange à competição poética que, até o fim da época Heian, ainda mantinha as antigas formas solenes, passa a ter um caráter recreativo, a partir da época do eximperador Go-Toba. E, na mesma época, assiste-se também ao abandono dos grandes templos, pelos monges que lá buscavam um refúgio para a busca do Verdadeiro Caminho e assistem a transformação do templo numa sociedade religiosa, onde há os mesmos vícios e disputas sociais da sociedade leiga. Muitos deles abandonam, então, os templos e instalam-se em humildes cabanas.

Realizando uma retrospectiva do processo de desenvolvimento do Budismo japonês, poder-se-ia resumi-lo, da seguinte maneira: o Budismo japonês, originalmente, implica no abandono do mundo terreno e dedicação e busca do Caminho Verdadeiro de Buda. O Budismo japonês, desde a sua transmissão, no entanto, desenvolveu-se, mantendo estreitos laços com o Estado e seus governantes. Desde a sua adoção como uma doutrina filosófica-religiosa, pelo Príncipe Shôtoku (574-622), passou a ser largamente prestigiado pela casa imperial.

Na época Nara (710-794), especialmente no reinado do imperador Shômu (701756), transformou-se, praticamente,em religião oficial, assumindo funções relevantes, relacionadas aos destinos do próprio Estado, constituindo-se como uma das principais causas que motivaram a transferência da Capital, de Nara (Heijôkyô) para Quioto (Heiankyô), em 794.

Na época Heian (794-1185), o Budismo, principalmente as seitas esotéricas, Shingon e Tendai, ganham inúmeros adeptos entre a nobreza, em função do poder milagroso de suas orações (kaji kitô). Essas orações que, até então, eram realizadas, visando a proteção do Estado, passam a ser solicitadas, em caráter particular, objetivando os anseios de ascensão social ou econômica, uma sucessão imperial conveniente, cura de enfermidades, parto bem-sucedido ou até controle sobre os fenômenos naturais, como a oração por precipitação atmosférica. Em meio a essa utilização pragmática do Budismo, surgem religiosos, como o monge Genshin , conhecido também como Eshin Sôzu (9421017) que, esquivando-se da fama, mantém-se recluso e dedica-se ao estudo do Budismo. Genshin, que escreveu o tratado budista mais antigo do Japão, Ôjôyôshû ( $A$ Salvação no Paraíso Jôdo), fundamentou as bases do pensamento Jôdo. Seguidores desse ensinamento que buscavam expressá-lo, através de suas próprias realizações, eram chamados hijiri ou shônin. A princípio, independentes de qualquer grupo religioso do Budismo de Heian, uns dedicavam-se à difusão da doutrina, peregrinando por várias partes do país e, outros, buscavam a tranqüilidade espiritual, retirado em cabanas construídas próximas, mas independentes do templo que deixaram, desejando fícar distante das disputas internas existentes no seio das grandes seitas.

O Budismo de Kamakura, representado por seitas como Jôdo, Jôdo Shinshû, Jishû, entres outras, diferentemente do Budismo de Heian que prometia graças imediatas e

5. Kouta, Zôgei e Imayô - tipos de poemas-canções que se tornaram populares, no fim da época Heian (744-1185) para início da época Kamakura (1185-1333), c que passaram a ser muito apreciados pela classe aristocrática da época. 
terrenas, pregava a salvação eterna, no paraíso Jôdo. A instabilidade da situação políticosocial, referida anteriormente, levou muitos leigos a tomarem hábitos monásticos, e a viver em retiro, afastado da tumultuada sociedade da época Chûsei, sem o objetivo de difundir ou pregar a doutrina de Buda como os monges, senão que buscar o seu próprio caminho, através do ensinamento de Buda.

Os que se retiravam para as cabanas construíam-nas, preferencialmente, nos sopés das montanhas, próximas a uma campina e, se pudessem ouvir o som de algum córrego ou fonte de água, seria o ideal. As cabanas, nos primeiros tempos, extremamente rústicas, construídas com o material encontrado na região, como bambus e folhas, foram se tornando maiores e mais bem montadas, com o passar do tempo. Seus moradores possuíam, como ideal, o desapego aos bens materiais e, para a sobrevivência, contavam com a ajuda da própria natureza, da prática da mendicância ou da caridade alheia. $O$ cotidiano era preenchido pela leitura do sutra, prática da ascese espiritual e, como atividades de lazer, a caminhada pela redondeza, a leitura, o escrever, a execução de algum instrumento musical. Essa vida em retiro adotada por escritores como Saigyô (1118-1190), Kamo no Chômei (1155-1216) ou Yoshida Kenkô (1282-1350), que, diferentemente dos literatos das épocas anteriores buscavam esse estilo de vida a nível de ideal, viveram-no efetivamente, levados, em grande parte, pelas circunstâncias da época.

Dessa forma, o termo inja adotado para nomear os escritores da época Chûsei, apresenta características diversas do termo tonseisha, por exemplo, que possui um sentido mais amplo, na medida em que todo aquele que, de certa forma, vivia afastado da sociedade, mas não se via obrigatoriamente a viver como um recluso, como os hijiri, os artistas, os mestres de renga, entre outros, era considerado tonseish $a^{6}$.

$\mathrm{O}$ termo inja apresenta uma acepção mais particular, visto que refere-se àquele que, não só se afasta da sociedade, mas mantém fortes laços com o Budismo, realiza a conversão religiosa (shukke), busca uma existência reclusa e dedica-se à atividade literária. A sua característica marcante, no entanto, parece residir no conflito travado em seu interior, entre a busca por uma existência verdadeira, através do ensinamento budista do desapego ao mundo terreno, e a dificuldade em se desligar completamente dele. Isso explica-se pelo fato de a conversão religiosa do inja não ser inspirado por uma vocação religiosa propriamente dita, mas possuir um caráter lenitivo, diante de uma circunstância adversa.

Essa tendência pode ser encontrada na trajetória seguida por três grandes nomes da Literatura dos Retirados, citados anteriormente: Saigyô, Kamo no Chômei e Yoshida Kenkô.

A família de Saigyô constitui ramificação da poderosa família Fujiwara da região de Ôshû (Nordeste do Japão). Desse modo, Saigyô serviu à organização burocrática central, inclusive fazendo parte do destacamento conhecido como hokumen no bushi, corpo de segurança do In (como era chamado o palácio dos ex-imperadores do governo paralelo, inse $i$, que chegou a deter força política considerável, no período de 1086 a 1185), na época do ex-imperador Toba (1103-1156). Aos 23 anos, no entanto, realiza shukke e inicia a sua vida em retiro, vivendo em rústicas cabanas ou peregrinando por

6. Cf. Saizô Kitô, "Inja Bungakuno Seiritsu" ("A Formação da Literatura dos Retirados"), Kokubungaku (Literatura Japonesa), número especial. Tóquio, Gakutôsha, vol. 19, n. 17, dez. 1974, p. 16. 
várias localidades do país, até a sua morte. Embora o motivo para tal decisão não tenha sido totalmente esclarecido, o poema escrito por ocasião do pedido de permissão, ao ex-imperador Toba, para abandonar a vida secular, faz-nos supor que um dos motivos tenha sido a busca do próprio sentido da vida, através do Caminho de Buda.

Por mais apegado que eu me sinta por este mundo,

Da mesma forma, seria eu considerado?

Talvez a salvação do eu,

Consista exatamente em abandoná-lo.

(Saigyô Jôninsh û - 637)

Kamo no Chômei teria nascido, provavelmente, em 1155. Considerando-se que, no ano seguinte, 1156, eclode a Revolta de Hôgen, quando torna-se patente e inegável a força dos grupos bushi, que, cada vez mais, foram galgando os degraus do poder, até o estabelecimento definitivo do governo militar, em 1192, significa que Chômei presenciou os últimos momentos da nobreza de Heian, vivendo o dia-a-dia de uma época de grandes e constantes transformações políticas, sociais e culturais.

Filho de um alto sacerdote xintoísta, Chômei recebeu educação aprimorada, aperfeiçoando-se na composição de poemas japoneses e chineses, na execução de instrumentos musicais. Com a morte prematura do pai, a vaga, até então, por ele ocupada é preenchida por Kamo no Sukesue, primo de segundo grau de Chômei. A dor pela perda do pai Chômei deixou registrada em poemas como:

O desejo de viver esvaiu-se.

Hei de atravessar a montanha que me separa da morte,

Para, pelo menos, assim,

Poder seguir os passos de meu pai.

O choque sofrido, quando da nomeação de Sukesue, deve ter sido, ainda maior, para Chômei, que tinha acabado de perder o pai. Anos mais tarde, quando Chômei contava já com quase cinqüenta anos, vaga o cargo de sacerdote, no santuário Shimokamo, o que reacende a esperança de poder seguir os passos do pai. A forte objeção imposta, por parte de seu tio Sukekane, que queria ver o seu filho, Sukeyori, no posto, e a sua conseqüente nomeação, parecem ter minado qualquer anseio que Chômei ainda guardasse com relação ao futuro. Chômei desaparece do círculo social e se retira para as montanhas, onde permanece, até a sua morte. O início que abre a sua obra Hôjôki (Anotações numa Cabana de Nove Metros Quadrados) parece refletir o sentimento de Chômei com relação a esse mundo que ele deixou para trás:

A água do rio que flui é incessante, mas não se trata da mesma água. As espumas que flutuam nos remansos, surgidos quando da mudança de curso da correnteza, ora se desfazem, ora se formam, tendo uma existência muito breve. Os homens e suas moradias deste mundo seguem igual curso. [...] A contínua transformação travada entre o dono e sua moradia, pode ser comparada à do orvalho que se deposita numa campânula. Ora resta a flor e o orvalho cai. E, mesmo que 
reste, ela seca ao sol matinal. Ora murcha a flor e o orvalho permanece. Mesmo que permaneça, ele jamais aguardará o entardecer.

Yoshida Kenkô acompanhou também uma época de transformações sócio-políticoculturais como Saigyô e Chômei, mas existe o espaço de um século separando-os. Podese dizer que, historicamente, Saigyô viveu o fim da época Heian (decadência da nobreza), Chômei, os primeiros tempos da época Kamakura (início do governo militar) e Kenkô, o fim da época Kamakura (quando a luta pelo poder dava-se entre os grandes grupos bushi, e a nobreza era já uma classe descartada, em termos de disputa política).

De origem nobre, Kenkô, assim como Saigyô, chegou a servir no corpo de segurança do In, na época do ex-imperador Go-Uda (1267-1324). Após a morte do eximperador, Kenkô realizou a conversão religiosa e, depois de peregrinar por algumas regiões do Japão, isolou-se nas imediações de Quioto. Em suas obras, Kenkô não faz transparecer, por nenhum momento, qualquer dúvida no que que se refere à excelência da cultura da nobreza, mas, por outro lado, mostra-se bastante lúcido, reconhecendo a inevitável decadência do mundo que essa cultura representa. Mas diferentemente de Chômei que assiste desiludido e passivo ao incessante fluir do rio, Kenkô encarava essa mudança de modo positivo e combatente, conforme trecho da sua obra Tsurezuregusa (Anotações no Ócio), episódio 155:

Os grandes acontecimentos essenciais como a vida, a velhice, a doença e a morte assemelham-se a um caudaloso rio, cuja correnteza parece transbordar do leito. O fluir é contínuo, jamais cessa, seguindo imediatamente o seu curso. Por isso, seja com relação às práticas budistas ou à vida terrena, em havendo algo imprescindível a ser realizado, faça-o, sem esperar pelo momento certo.

Saigyô que buscou o refúgio solitário no seio da natureza, Chômei que se isolou, repentinamente, numa cabana, ao pé da montanha, como que fugindo da Capital, e Kenkô que parece ter encontrado a liberdade de um "tempo monótono e uma vida monótona"7 que ele chama de tsurezure ("ócio"). Independente dos motivos de cada um, trata-se de três homens que optaram pela vida de "retirado", diante do contraditório destino a eles imposto pela História: manter e ansiar pelos valores antigos da sua classe, agora decadente, e viver o cotidiano de uma nova sociedade que dita seus novos valores. Parece-nos, assim, que a Literatura dos Retirados nasceu, em grande parte, das mãos de homens que, diante da inevitável e inabalável realidade, optaram por realizar um sábio "retiro"estratégico que, por um lado, proporciona-lhes um conforto espiritual e, por outro lado, oferece-lhes uma maior liberdade intelectual e disponibilidade de tempo, pois que estavam isentos de manterem qualquer compromisso ou deveres sociais.

Pela sua sabedoria, idealismo e desprendimento, posso dizer que tive o privilégio de conviver com um inja dos tempos modernos, inveterado tabagista e apreciador de um bom destilado. Agora, ele vive, em retiro, num plano superior.

7. Cf. Sumito Miki, Chûsei Inja Bungaku (Literatura dos Retirados da Época Chûsei). Tóquio, Gakuseisha, 1976, p. 160. 


\section{Bibliografia}

ARIYOSHI, Tamotsu. Saigyô. Tóquio Shûeisha, 1985.

ITô, Hiroyuki et alii. "Chûsei Inja Bungaku" ("Literatura dos Retirados da Época Chûsei"). Col. Shinpojiumu - Nihon Bungaku 6. Tóquio, Gakuseisha, 1976.

KARAKI, Junzô et alii. "Injatachi" ("Os Retirados"). Kokubungaku (Literatura Japonesa), número especial. Tóquio, Gakutôsha, vol. 19, n. 14, dez. 1974.

KINO, Yoshikazu e MIKI, Sumito. Bukkyô Bungakuno Koten - Ge (Clássicos da Literatura Budista - Parte 2). Tóquio, Yûhikaku, 1980.

MIKI, Sumito. Hôjôki (Anotações num Cabana de Nove Metros Quadrados). Tóquio, Sanseidô, 1977.

Nihon Koten Bungaku DaijtTEn Henshû ShÛInKal (org.). Nihon Koten Bungaku Daijiten Dai Ikkan (Grande Dicionário da Literatura Clássica Japonesa - vol. I). Tóquio, Iwanami, 1983.

ORIKUCHI, Shinobu. "Nyôbô Bungakukara Inja Bungakue" ("Literatura das Damas da Corte para a Literatura dos Retirados"). Origuchi Hakase Kodai Kenkyûjo (org.). Origuchi Shinobu Zenshû (Obras Completas de Orikuchi Shinobu), vol. 1. Tóquio, Chûô Kôronsha, 1965, pp. 265-320.

SAIGô, Nobutsuna et alii. "Inja Bungaku" ("Literatura dos Retirados"). Nihon Bungakuno Koten (Clássicos da Literatura Japonesa). Tóquio, Iwanami Shoten, 1978, pp. 113-127.

SHIRAISHI, Daiji et alii (org.). "Inja Seikatsu" ("Vida em Retiro"). Koten Dokkai Jiten (Dicionário de Leitura e Interpretação da Literatura Clássica). Tóquio, Tôkyôdô, 1966, pp. 10-13.

TOMIKURA, Tokujirô (org.). Tsurezuregusa. Hôjôki (Anotações no Ócio. Anotaçōes numa Cabana de Nove Metros Quadrados). Col. Nihon Koten Kanshô Kôzô, vol. 13. Tóquio, Kadokawa, 1969.

Luiza Nana Yoshida

Centro de Estudos Japoneses da USP Curso de Língua e Literatura Japonesa - FFLCH-USP 